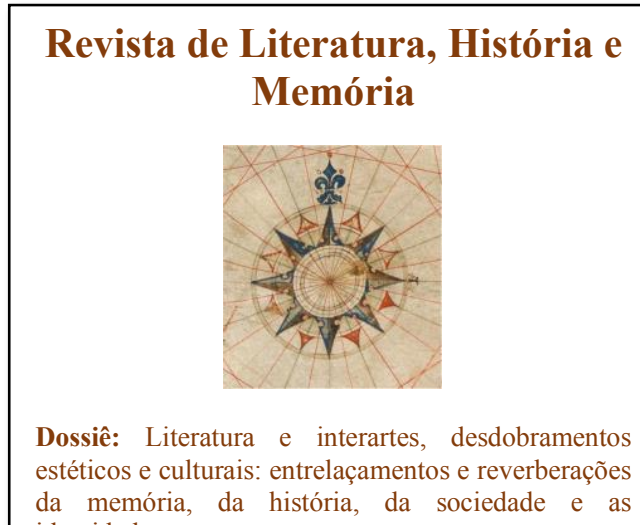
identidades

ISSN 1983-1498

VOL. 16 - $\mathbf{N}^{\mathrm{o}} 28$ - 2020

U N I O E S T E / CA S C A V E L - p. 24-45

\title{
NARRATIVAS DE CORPOS E IDENTIDADES EM DOCUMENTÁRIOS SOBRE MULHERES LATINO- AMERICANAS
}

\section{Narratives of bodies and identities in documentary films about latin american women}

\section{Meire Oliveira Silva ${ }^{1}$}

RESUMO: O presente artigo objetiva analisar os documentários Simplesmente Jenny (1977) e Meu corpo, minha vida (2017) que, em um período de 40 anos, unem dois momentos distintos do cinema de Helena Solberg. Ambos estão ancorados na observação das existências de mulheres permeadas por ideais sexistas (GONZÁLEZ, 1988) no curso das Artes, Literaturas e História. Para tanto, uma abordagem voltada às relações entre esses saberes, a partir dos estudos comparados e interartes (CLÜVER, 1997), norteará estas reflexões propostas. Tais filmes pautam-se por imposições sociais que propiciam o auge da violência contra a mulher existencial e politicamente (FRIEDAN, 1971), em meio a sociedades muito marcadas por cicatrizes totalitárias de origem colonial. Desse modo, os estudos de gênero (LUGONES, 2008) e culturais serão uma possibilidade de compreender essas trajetórias de mulheres nas quais os reflexos coloniais deflagram momentos históricos repletos de lacunas e fissuras sociais. Essas formações problemáticas encontram ressonância em discursos hegemônicos que estruturalmente embasaram as sociedades latino-americanas (ORTIZ, 2006) diante da incessante interrupção de expressões, vozes e vivências.

PALAVRAS-CHAVE: Helena Solberg; Cinema documentário; América Latina; Literatura Comparada; Estudos Interartes.

\begin{abstract}
This paper aims to analyze the documentary films Simplesmente Jenny (1977) and Meu corpo, minha vida (2017), by Helena Solberg, in 40 years of her filmography. Both of them focus the existence of women under pressure of sexist ideals (GONZÁLEZ, 1988) in Arts, Literature and History. Therefore, an approach on Comparative Literature and Inter-Art Studies (CLÜVER, 1997), will guide these proposed reflections. Those films are guided by social criticism about the height of political and existential violences against women (FRIEDAN, 1971), in the societies very marked by totalitarian scars of colonial sources. In this way, Gender and Cultural Studies (LUGONES, 2008) will be a possibility to understand these trajectories of women in which the colonial reflexes trigger historical moments full of social gaps. Thus, these problematic formations find resonance in hegemonic discourses that structurally support Latin American societies (ORTIZ, 2006) with the incessant interruption of expressions, voices and experiences.
\end{abstract}

KEYWORDS: Helena Solberg; Documentary film; Latin America; Comparative Literature; Inter-Art Studies.

Pensar o cinema como instrumento de comunicação de massa e conceber a potência de seu alcance por meio de abordagens sociais e políticas configura-se como uma possibilidade de leitura de um momento histórico. Não só as contribuições de suas abordagens dos

\footnotetext{
${ }^{1}$ Mestre e Doutora em Teoria Literária e Literatura Comparada pela Faculdade de Filosofia, Letras e Ciências Humanas pela Universidade de São Paulo (FFLCH-USP). Docente do Curso de Letras na Universidade Estadual do Oeste do Paraná (UNIOESTE, Campus de Foz do Iguaçu).
} 
acontecimentos, mas o exame de seus contextos de realização que se pretende documental ao sugerir contornos históricos no que se refere à produção das imagens. E o cinema de Helena Solberg segue uma marca que talvez seja visibilizar as mulheres, sobretudo, as de origem latino-americana em constante exame dos percalços que erigiram suas trajetórias. Pode-se então filiar essa filmografia a uma vertente que considera o cinema como possível fonte histórica para se compreender as narrativas de mulheres latino-americanas entre 1977 e 2017 ? Sob uma análise em perspectiva comparativa e interartes, é possível encontrar questões de proximidades históricas e de formação, inclusive colonial, europeia e cristã, como influência norteadora dos conflitos vivenciados por Jenny e Jandyra, respectivamente, em Simplesmente Jenny e Meu corpo, minha vida, em um intervalo de 40 anos, aproximando ambas as obras de outras, produzidas no mesmo tempo histórico? E, mais ainda: a abordagem de suas narrativas pessoais reflete a história das sociedades das quais essas mulheres muito jovens são vítimas? Além disso, é preciso considerar que ambos os filmes mostram dois períodos distintos da obra da cineasta: desde o início de suas incursões pela América Latina, ainda na juventude e quando autoexilada; e já de volta ao Brasil, em seu cinema recente, que ainda segue em realização na maturidade.

\section{O CINEMA DE HELENA SOLBERG}

Para descrever a filmografia de Helena Solberg e sua temática predominantemente voltada à mulher, é preciso remontar à sua primeira realização, o documentário A entrevista (1966). Ainda no Brasil, antes de seu exílio voluntário para residir e realizar cinema nos Estados Unidos, a cineasta estreou em meio à efervescência cinemanovista com esse documentário que se ancorava na observação da vida de universitárias. Muitas delas, recémcasadas, comentaram o papel do matrimônio em suas vidas. Suas origens privilegiadas de meninas educadas em colégios de freiras, residentes da zona sul carioca, pautavam o tom do filme: o retrato de mulheres jovens oriundas de uma classe social específica e suas problemáticas. A partir daí, a cineasta constrói uma análise de sua própria condição social para investigar aquele país onde nascera, mas que lhe era desconhecido. Ou o Brasil mormente retratado por seus colegas contemporâneos do Cinema Novo que aspiravam fazer revolução através dos filmes a educar o povo.

Contudo, os acontecimentos apresentaram-se impiedosos diante da derrocada dos ideais advindos de órgãos politizados ligados à disseminação de arte e conhecimento, como o CPC (Centro Popular de Cultura) e o ISEB (Instituto Superior de Estudos Brasileiros). A 
cultura dos anos 1960 assistiu ao golpe civil-militar e a afrontas democráticas, apesar de ter produzido arte de inegável qualidade. De fato, o cinema, o teatro, a música e as demais expressões artísticas da época estavam comprometidas com a crença na transformação social, por mais que soasse como utopia e rebeldia juvenis:

[...] Hoje, tornou-se já lugar-comum denunciar essa ilusão, mas, em 195964, ela era proclamada em diferentes focos de reflexão, notadamente no Instituto Superior de Estudos Brasileiros (ISEB), onde encontramos a ideia que era urgente formular a teoria do desenvolvimento, da libertação nacional, porque o momento histórico o exigia e porque tal perspectiva, amadurecida, estava no inconsciente do povo, como uma espécie de ideologia balbuciante e não formulada, sendo tarefa do intelectual explicitála. Na perspectiva do ISEB, predominava, na concepção mesma do trabalho teórico, aquela noção humanista da história como projeto, onde a naçãosujeito (substituta da consciência individual-sujeito de Jean-Paul Sartre) definiria suas opções, se autodeterminando e moldando seu futuro" (XAVIER, 2007, p. 189).

E as resistências pela chamada "libertação nacional" impostas pela ala intelectualizada que se afirmava como detentora de uma voz capaz de projetar a nação frente aos seus paradoxos de formação, também iam ao encontro dos mesmos ideais, no que se refere ao povo como agente transformador dessa nação. Esse povo e sua realidade precisavam ser desvendados e consagrados como símbolos de uma luta ${ }^{2}$, especialmente no pensamento de Glauber Rocha (1963, p. 165), tomado até hoje como símbolo da estética do Cinema Novo:

[...] Dentro dessa perspectiva, o colonialismo impõe aos países colonizados uma dupla dominação, ela é exploração econômica das matérias-primas e importação de produtos acabados, mas sobretudo dominação cultural. A analogia com a economia levará alguns autores a afirmar que a importação do Cadillac, da Coca-Cola, do chiclete, do cinema implica o consumo (antropofágico?) do Ser do Outro. Dito de outra forma, o colonizado importa a sua consciência, ele é o reflexo do reflexo. Esse tipo de análise marca até hoje as discussões sobre cultura brasileira [...] Se, como dizem alguns isebianos, o Ser do homem colonizado está alienado no Ser do Outro, é necessário dar início a um movimento que restitua ao colonizado a sua "essência". Isto só pode ocorrer se o discurso extravasar do terreno filosófico para o domínio político (ORTIZ, 2006, pp. 58-59)³.

\footnotetext{
${ }^{2}$ Por mais que essa ideia de levar o povo à luta, nos anos 1950/1960 seja até reducionista e contraditória. Logo, o exemplo do CPC - herdeiros das ideias nacionalistas surgidas em 1950 - na ideia de produzir uma arte popular suscita discussões em torno de Carlos Estevam Martins - autor do manifesto do CPC da UNE -, Leon Hirszman, Oduvaldo Viana Filho e Ferreira Gullar.

${ }^{3}$ Para aprofundar essas hipóteses é desejável que se complemente com as investigações dos escritos de Frantz Fanon, Roland Corbisier e Jean-Paul Sartre, citadas por Renato Ortiz (2006, pp. 61-62), sobre as relações de dominação - colonização - na cultura nacional.
} 
Embora declare ter sido contemporânea, mas não necessariamente vinculada ao cinemanovismo tanto estética como ideologicamente (INTERVIEW LAS 460/560), Helena Solberg também busca desvendar a dominação cultural exercida pelos Estados Unidos sobre os países subdesenvolvidos por meio de questões socioeconômicas de raízes históricas. Porém, somente quando sai do Brasil em 1970, no auge dos chamados "anos de chumbo". Ao residir nos Estados Unidos e viajar pelos países da América Central e do Sul, a cineasta se depara, no encalço da realidade latino-americana, com miséria e explorações. Logo, este estudo buscará estabelecer uma linha comparativa entre Simplesmente Jenny (1977) e Meu corpo, minha vida (2017) para tentar unir duas pontas da filmografia de Solberg. Entre a juventude e a maturidade dessa obra, será investigado de que maneira se afirmou paulatinamente como expressão feminina cujas opressões se desnudam a cada filme em profunda consonância com seu tempo.

\section{QUESTÕES DE POLÍTICA, HISTÓRIA E GÊNERO}

Sendo assim, é possível notar que toda a descrição do mal-estar - freudiano - na cultura transposto à condição feminina, é o mote da primeira incursão cinematográfica de Solberg, ainda no Brasil. Mesmo assim, um Brasil distante da América Latina cujo microcosmo estava situado à beira-mar dos cartões postais do Rio de Janeiro dos anos 1960. De certa forma, esse primeiro olhar pode inclusive ser tomado como o contraponto do que produziu posteriormente. No entanto, estava voltada para seu universo social, ao acompanhar os anseios de outras jovens contemporâneas, diante do matrimônio, da família e da propriedade. A realidade dessas mulheres estava começando a ser desvendada pela chamada "segunda onda feminista". Nos Estados Unidos, essas pautas foram lideradas por Betty Friedan, autora de A mística feminina (1963), que proporcionou grande avanço para os debates de gênero da época, em relação à equidade, inalcançável para essas mulheres privilegiadas financeiramente.

Justamente por terem sido criadas em um sistema educacional e religioso que lhes incutia uma resignação de servir apenas à perpetuação da existência de uma "prole" - neste caso, dominante, devido à origem social. Assim, a mulher e seus filhos estariam automaticamente comprometidos com a manutenção do sistema de dominação da força de trabalho que movimentaria as riquezas do país. E suas posses seriam preservadas e aumentadas por meio de uma união às quais estavam destinadas. Muitas das depoentes do curta revelam orgulho em ocupar esse papel-chave, na concepção da ideia de uma mulher 
envolta por uma constituição somente biológica. Betty Friedan, ao indagar o mito da mulher como pivô desse estilo de vida convencional, abalou o que se afirmava como a comprovação de american way of life: valores pautados por consumo e reprodução, em lógica capitalista implacável. A cineasta reconhece, ao fazer um balanço de sua obra, que trilhou um caminho rumo ao aperfeiçoamento de posições e redescobertas, quando já impedida de filmar no Brasil.

Nessa linha, é fundamental dar lugar ao reconhecimento da cineasta como mulher nascida na América Latina ao discutir o desempenho de papéis de gênero. Portanto, vale enfatizar que, em 1966, com a fundação da NOW (National Organization for Women) - com Friedan a representar suas frentes -, o projeto de disseminação da ideia de defesa e equidade dos direitos femininos foi consagrado por meio de uma reunião expressiva de mulheres de variadas origens sociais e étnicas que marcharam em 26 de agosto de 1970. Tudo isso se dava em meio às ferrenhas críticas da imprensa em torno das causas feministas, sendo demonizadas como anti-homens e antifamílias. Ou atribuindo a Friedan a alcunha de "inimiga pessoal da mulher” (RODRIGUES, 1995), segundo o dramaturgo e jornalista Nelson Rodrigues, na ocasião da visita da teórica norte-americana ao Brasil.

Em crônica, o jornalista chegou a classificá-la como "líder do antifeminismo" (1995) pelo fato de defender a tese de que a mulher era oprimida pelas exigências de uma "sociedade de consumo" (1995). A confusão de conceitos e preconceitos se derrama por toda a crônica e reitera o fato de que as funções da maternidade e do patrimônio eram a "dádiva" da mulher imbuída de "feminilidade". Ao passo que o dramaturgo também não reconhece o feminismo como uma corrente teórico-política que investiga as relações assimétricas de dominação e poder entre os gêneros. Parece compreender a palavra "feminismo" - já que etimologicamente semelhante ao vocábulo "feminino" - como expressão de fragilidade atribuída à mulher. De modo que essa associação pode ser uma maneira de desvelar o pensamento de parcela da sociedade à época de realização do filme.

Ainda que em meios considerados intelectualizados, aqueles anos 1960 no Brasil foram os mesmos que assistiram a um golpe civil-empresarial e militar ao presidente João Goulart. Desde que tomou posse, em 1961, as iniciativas associadas ao seu governo demonstraram interesse pelos setores agrário, educacional, fiscal, bancário, entre outros, visando à diminuição de desigualdades estruturais. A ala conservadora viu-se contrariada diante das chamadas "reformas de base". Isso contribuiu para a deposição de Goulart através de uma série de medidas consideradas defensoras da família e dos costumes tradicionais. A 
$\mathrm{CAMDE}^{4}$ foi uma das associações cuja participação na frente "anticomunista" foi significativa. Suas lideranças eram de origem católica. Não é estranho, portanto, reencontrar os mesmos artifícios em discursos atuais acerca das vidas das mulheres como se fossem seres desprovidos de seus corpos, justamente por grupos religiosos. Talvez, a cineasta não imaginasse que essas seriam reflexões norteadoras de toda a sua trajetória fílmica. E sair do Rio de Janeiro apurou inegavelmente o seu olhar.

Reconhecer-se, nos Estados Unidos, como latina, também direcionou a percepção da cineasta aos entrelaçamentos de gênero, classe e raça. Percebeu também que as mulheres se encontravam em situações de maior vulnerabilidade nos países da América Latina, de acordo com as imposições resultantes das exclusões econômicas, políticas, educacionais etc., que acirram as desigualdades de gênero. Desse modo, a obra de Solberg passa por verdadeira mudança a partir dos filmes realizados em torno da realidade latino-americana:

...para mim, a descoberta da América Latina foi muito importante. Porque o Brasil, como todos os países muito grandes que são muito virados para si mesmos... e a gente nunca se sentiu parte do resto da América, tanto que se esnobava os bolivianos e peruanos [...] eu me lembro de que nós sabíamos mais do que estava acontecendo na Europa e nos Estados Unidos do que na América Latina. Havia um certo esnobismo e, para mim, foi uma revelação [...] olhar o país de fora, o de fora para dentro, é muito curioso e é importante. E eu acho que eu tenho agora esses dois olhares e isso é uma vantagem. Eu sempre fui estrangeira neste planeta, eu acho. Meu pai era norueguês, eu me casei com americanos, duas vezes. [...] Por estar fora, eu era vista como uma latina. Para eles [norte-americanos e europeus], não há distinção, de qualquer lugar da América do Sul, é tudo latino (INTERVIEW LAS 460/560).

Helena Solberg também acompanhou a condição de invisibilidade relegada à participação das mulheres na economia dos países nos quais filmou. Fato relacionado e abordado no início de Simplesmente Jenny como atrelado aos primórdios das civilizações conquistadas por colonizadores. Da mesma forma, um estudo sobre as complexidades do feminino emerge historicamente junto à prerrogativa de que o "destino de mulher"5 a impele à maternidade e à principal força de trabalho também doméstico e familiar e essas imposições tradicionais destacam a figura feminina imersa em nuances que, talvez, a associem à sensação de deslocamento e insatisfação:

\footnotetext{
${ }^{4}$ Campanha da Mulher pela Democracia (1962-1970) de oposição a João Goulart, e em defesa de medidas assistencialistas e conservadoras.

${ }^{5}$ Cf. BEAUVOIR (1980) LISPECTOR (1998), em escritos cujas primeiras publicações datam, respectivamente, de 1949 (O segundo sexo) e 1960 (Laços de família), exceto seu conto "Amor", publicado previamente na Revista Senhor e em outros meios, coincidentemente, no mesmo ano da obra de Simone de Beauvoir.
} 
Embora inseridas em espaços geográficos definidos, suas personagens mantêm uma espécie de decalagem, de deslocamento em relação a esses espaços. Nesse sentido, apresentam um olhar de fora, estrangeiro. É como se essas personagens se sentissem um pouco estrangeiras em suas pátrias, o que lhes proporciona um olhar crítico, diferenciado. Nas palavras da cineasta: "Eu gosto muito do estrangeiro. O estrangeiro no sentido de Camus (2008a): L'étranger. A ideia do outsider. Daquele que está sempre um pouco fora. Eu acho isso essencial". Em geral, essas personagens estão em processo de transição. Estão divididas, fragmentadas, cabendo aos filmes a investigação e reconstrução de suas identidades (TAVARES, 2011, p. 23).

Pode-se levantar uma breve linha cronológica, que não se pretende exata ou reducionista, de modo a tentar entrever hipóteses para a concepção em torno da construção da mulher e dos papeis a ela reservados. Se em Roma havia a dicotomia entre a mãe e a adúltera; na Grécia, viu-se a emersão da deusa da natureza, chamada como o mal capaz de ruir as estruturas patriarcais. Já na Idade Média havia a imagem da mulher inalcançável, de figura etérea e intangível. A perpetuação de estereótipos ligados à santidade permaneceu até o final do século XIX, perpassando as morais e tradições exigidas pela Era Vitoriana. A psicanálise de Sigmund Freud, no século XX, transformaria as concepções de corpos e sexualidades, mas ainda insistiria na cisão da mulher. A feminilidade então passaria a ser vista como uma condição em que, diante do não extravasamento dos desejos, poderia culminar em histeria. A mulher como uma constituição dupla também surgiria e seria continuamente representada pelas narrativas originárias entre lendas, contos de fadas e cantigas folclóricas, moldando o imaginário popular.

O maniqueísmo depreendido do conceito de feminilidade fomentaria uma recusa à compreensão de sua natureza como produto de uma construção social. Ao contrário, contribuiria para a manutenção de um determinismo biológico em figuras baseadas em discursos misóginos acerca do corpo feminino visto de modo reificado, produto de consumo e exploração (FEDERICI, 2017). Tais movimentos geram o silenciamento das mulheres ao longo da História com a mesma intensidade em que se reproduzem discursos sobre suas existências. Helena Solberg sensivelmente desenvolve esses elementos em seus filmes: abrir espaço para as vozes de mulheres que precisam falar por si, sobre si mesmas e acerca do mundo. Essas vozes são testemunhos do momento histórico em cada país visitado e a cada realidade encontrada. E, partir do Brasil, de formação historicamente controversa, para falar sobre as mulheres, haveria também um exercício instigante mesmo ao ser considerada a sua origem privilegiada. Até em meio aos privilégios havia a questão de gênero e isso se mostra uma temática central desde seu primeiro documentário. 


\section{MULHERES LATINO-AMERICANAS}

Após esse breve panorama do que significaram os levantes feministas até os anos 1970, existe uma ruptura crítica com o universo de questionamento em Simplesmente Jenny. Afinal, quais mulheres podem se organizar em torno da defesa de suas pautas quando a opressão que sofrem independe de reinvindicações e são ancestrais porque calcadas em uma formação histórica de exclusões? O início do documentário de 1977 se dá em um salão de beleza junto a depoimentos de moças e rapazes muito jovens acerca dos seus papeis em sociedade. Logo a seguir, centra-se no depoimento das jovens Marly, Patrícia e Jenny para traçar uma retomada histórica da conjuntura social que vitima as mulheres na Bolívia; relegando-as à prostituição e usurpação de seus corpos, identidades e existências. É a partir do olhar enclausurado do reformatório que a narrativa se constrói em torno de um eixo condutor que dilacera os limites das formações históricas para deflagrar a situação de abandono de jovens envoltas em sonhos de casamento, família e profissão erigidos pela mesma sociedade que lhes confere contínua exclusão social. A temática feminista se amplia para o questionamento de um discurso de desigualdade imposto por condições diversas relativas à pobreza e à origem étnica.

Dessa forma, delineia-se o retrato das mulheres como existências relegadas ao jugo dominador. No documentário, a mulher latino-americana é mostrada em uma duplicidade: de um lado, as de origem europeia; de outro, as descendentes indígenas, numa clara abordagem dos cruzamentos raciais impostos desde a colonização. Ao ser iniciado com a imagem de uma modelo de traços tipicamente europeus dançando ao som da canção que narra a trajetória de uma mariposa frágil necessitada de amor, proteção e carinho; está posta a incessante comparação entre a nativa e a mulher europeia como a virgem etérea permeada por santidades $^{6}$. Esta trilha reproduz o padrão de beleza europeu amplamente disseminado por meios de comunicação e indústria da moda a ditarem regras estéticas dirigidas à coerção de quem não se encaixa em tais moldes de submissão a prerrogativas e exigências diversas para alcance de alguma inserção ou aceitação social.

O documentário mescla depoimentos a outras imagens e sons captados diretamente. Ao mesmo tempo os combina novamente a outros tipos de sons, como os da banda sonora e outras imagens escolhidas pela própria diretora - de salões de cabeleireiro e poses de atrizes e

\footnotetext{
${ }^{6}$ No romance Iracema (1865), clássico da literatura romântica indianista, escrito por José de Alencar, a personagem do colonizador europeu Martim, vê-se imersa em grande dúvida: render-se às tentações da índia personagem-título, Iracema - descrita como "morena dos ardentes desejos" - ou manter-se fiel à noiva - "virgem dos castos amores" - que havia deixado na Europa.
} 
modelos. Esse contraste dará o tom do filme que, para além do registro, parece esboçar uma marcação de autoria diegética por meio do posicionamento sobre o assunto pesquisado: a mulher latino-americana em seu cotidiano repleto de complexidades históricas e socioculturais. A diegese remonta à trajetória do pioneirismo colonizador desde a primeira cena. Através da imagem de uma mulher envolta em tecidos esvoaçantes de maneira idealizada, emergem - em choque - os próximos rostos das moças bolivianas que fornecerão depoimentos quando ainda internas de um reformatório. Local para onde foram levadas após diversas violências de seus corpos, entre estupros e prostituição. Corpos carregados de mácula e "pecado", segundo os julgamentos cristãos. O ideal de beleza e pureza, assim como o padrão de conduta feminina, será questionado o tempo todo pela sequência de imagens que retoma a ideia de uma feminilidade. Esta, contrastante. Ou questionando-se quais paradigmas devem ser seguidos até o alcance da aspiração desse ideal de mulher exigido a fim de que não haja retaliações sociais, como os abusos ancestrais perpetuados historicamente. Assim, seguem-se imagens de mulheres em salão de beleza em busca da perfeição veiculada pela mídia por meio de manequins de lojas e modelos que estampam as capas de revistas, mas também ideais disseminados pelas literaturas - de viagem, documentais ou ficcionais voltadas ao encontro dos colonizadores europeus nas terras selvagens.

Se atualmente observa-se cada vez maior reivindicação por autenticidade que valorize a diversidade de corpos e identidades; entre os anos 1960/1970 com a chamada revolução sexual - também fomentada pela pílula anticoncepcional - ainda não havia significativa preocupação com a libertação de todos os tipos de corpos e vivências, sobretudo nos ecos latino-americanos, africanos ou asiáticos oprimidos pela visão eurocêntrica de padrões estéticos. A própria abertura do filme chama atenção para o fato de que a narrativa terá um recorte histórico para sustentar as análises acerca das vidas das mulheres latino-americanas em sociedades pautadas por muitos resquícios de origem colonial. A Carta de Américo Vespúcio, na ocasião da chegada às Ilhas Canárias, serve como locução off ilustrada por mapas e outros recursos imagéticos que conduzem o olhar do espectador para um momento pedagogicamente comprometido com a elaboração e defesa de um ponto de vista cuja premissa servirá como embasamento para a construção da lógica que relacionará a opressão de gênero aos seus entrelaçamentos históricos de origem colonial e escravocrata e também à manutenção de uma lógica perversa de dominação atrelada ao sistema capitalista. A socióloga argentina e ativista feminista María Lugones alertou para as questões de gênero em dialogismo com os pressupostos teóricos do sociólogo peruano Aníbal Quijano, no campo dos estudos decoloniais, como possíveis ainda de questionamento, já que muito maleáveis na 
análise dos impactos dos estudos culturais:

Podemos ver que el alcance de la colonialidad del género en el análisis de Quijano es demasiado limitado. Para definir el alcance del género, Quijano asume la mayor parte de lo prescripto por los términos del lado visible/claro hegemónico del sistema de género colonial/moderno. He tomado un camino que me ha llevado afuera del modelo de Quijano de la colonialidad del género para revelar lo que el modelo oculta, o que no nos permite considerar, en el alcance mismo del sistema de género del capitalismo global eurocentrado (LUGONES, 2008, p. 88).

As primeiras sequências, com a descrição do que representou a colonização nas Américas, a partir dos relatos de Vespúcio em suas missivas, traz relações diretas entre a opressão de gênero e as origens sistema colonial nas terras conquistadas. Seguem-se as entrevistas com moças muito jovens em sonhos inconciliáveis pelas mesmas relativizações acerca do comportamento e das inclinações dos homens em relação à sexualidade. Nesse momento, a confissão do estupro como iminência a rondar a condição dessas meninas entrevistadas, em certa conivência de uma sociedade completamente alheia aos problemas enfrentados pelas mulheres atingidas pela miséria, o documentário desenvolve a narrativa pautada pela realidade vivenciada na América Latina com destaque às violências de gênero. A condição de precariedade das habitações e das mínimas exigências quanto ao sanitarismo apresenta-se como cotidiano das três moças entrevistadas. Ainda assim, almejam realizar o sonho do casamento e da maternidade, diante do mito do "pecado original no processo de degradação social que as mulheres sofreram com a chegada do capitalismo [...] a misoginia que ainda caracteriza a prática institucional e as relações entre homens e mulheres" (FEDERICI, 2017, p. 292).

A exploração de riquezas, com a chegada das primeiras tripulações nas naus colonizadoras, associa o descobrimento das terras aos minérios extraídos e às primeiras violências contra as populações indígenas. E toda a dominação exercida de modo impetuoso pelo colonizador estava amparada nas teorias de que os povos originários eram inferiores, como consta nas próprias cartas dessas expedições e na carta lida nas cenas de abertura do filme. Mostra-se ali que aquele primeiro encontro entre nativos e desbravadores viajantes deflagrou contrastes a partir da nudez de índios, fossem homens ou mulheres. E essa nudez passou a validar a exploração de seus corpos ofertados aos colonizadores aportados como mais mercadorias provenientes da terra. A tríplice formada por colonização, patriarcado e violência contra o gênero feminino parece conduzir o espectador a narrativas históricas a fim de reproduzir no presente o que foi realizado no passado. Além da ideia de uma desordenada 
loucura e descontrole das mulheres em relação aos desejos sexuais como nas literaturas de ficção que tratam do assunto - nas obras da Literatura Brasileira referentes ao Romantismo e ao Naturalismo ${ }^{7}$, por exemplo, - e inferiorizam ainda mais, já que os homens nativos parecem, nesse sentido, gozar de maior privilégio dada questão de até, de certa forma, se identificar com o colonizador pela categoria do cis hetero patriarcado. E não só as literaturas de ficção e históricas trazem esses registros, mas também aqueles presentes nas artes plásticas com os artistas das Missões Francesa - e Austríaca - que aqui vieram para documentar os costumes do Brasil colonial e imperial que se estenderam aos estudos modernistas da década de 1930 ainda obstinados a encampar o projeto identitário e cultural do país:

Talvez, na década de 1930, a obra de Gilberto Freyre, ao reabilitar a contribuição dos escravos africanos para a cultura brasileira, tenha sido relevante para o entendimento do esforço de Debret em tentar mostrar que na cidade em que viveu durante 15 anos, os principais atores da vida econômica eram esses diferentes grupos de escravos. Mercadoria humana desembarcada, negros libertos, "escravos de ganho" ativos em toda a cidade, os trabalhadores africanos no Rio de Janeiro aos quais Debret dedica sua atenção detalhada e constante, são homens e mulheres cuja integração lenta a uma população local, cada vez mais miscigenada, dará força ao advento da nação brasileira (LEENHARDT, 2013, p. 519).

Tais retratos desvelados pelos projetos colonizadores deflagram aspectos relevantes concernentes às intersecções raciais e de gênero. Exclusões e extermínios são operados por meio das sucessivas violências desferidas contra mulheres cujas ancestralidades foram colonizadas e continuam a sofrer as consequências daquele passado em diversas áreas de suas vidas. Os mecanismos capitalistas de controle as inferiorizam nos âmbitos econômico, político e social e exercem influência até sobre seus corpos e questões reprodutivas, como demonstram as teorias relativas ao controle de natalidade e à interrupção de gravidez indesejada.

A imagem da mulher na história do Brasil em período colonial, atendo-se, por exemplo ao pintor e membro da Missão Artística Francesa, Jean Baptiste Debret e o sociólogo pernambucano Gilberto Freyre, por exemplo, oscila entre idealização e estereótipos em país historicamente marcado pela escravidão e pela colonização. Para Freyre ao aludir à se sensualidade das mulheres cuja ascendência foi escravizada nestas terras fazendo um ensaio pautado pela observação desse encontro étnico: Pode-se, entretanto, afirmar

\footnotetext{
${ }^{7}$ A personagem Rita Baiana, do romance $O$ cortiço (1890), de Aluísio Azevedo, por exemplo, é a impetuosa mulata que exerce grande tentação ao português Jerônimo, que larga mulher, filha e trabalho, para se aventurar nas graças e meneios da nativa que dançava sensualmente requebrando os quadris e desnudando coxas e ombros sem pudores, fazendo-lhe entregar-se a bebedeiras e luxúrias desmedidas, "abrasileirando-se".
} 
que a mulher morena tem sido a preferida dos portugueses para o amor, pelo menos para o amor físico. A moda de mulher loura, limitada aliás às classes altas, terá sido antes a repercussão de influências exteriores do que a expressão de genuíno gosto nacional. Com relação ao Brasil, que o diga o ditado: 'Branca para casar, mulata para f..., negra para trabalhar, ditado em que se sente, ao lado do convencionalismo social da superioridade da mulher branca e da inferioridade da preta, a preferência sexual pela mulata. Aliás, o nosso lirismo amoroso não revela outra tendência senão a glorificação da mulata, da cabocla, da morena celebrada pela beleza dos seus olhos, pelos seus dengues, quindins e embelegos muito mais do que as "virgens pálidas" e as "louras donzelas". Estas surgem em um ou em outro soneto, em uma ou em outra modinha do século XVI ou XIX. Mas sem o relevo das outras" (FREYRE, 2003, p. 71-72).

Uma das mulheres - com feições indígenas originárias das populações de cultura précolombiana - entrevistadas por Helena Solberg, é uma mãe que diz ser mais fácil ter filhos [homens] pelo fato de as meninas serem "muito maltratadas". Este, o modo eufemístico de se referir aos estupros naturalizados principalmente em países onde a pobreza e o subdesenvolvimento denunciam as desigualdades na distribuição de riquezas. Mortalidade e prostituição infantis também são temas abordados. A partir disso, o cristianismo apresenta-se, ainda mais incisivamente, revestido pela ideia de que existe um ideal de expressão da feminilidade capaz de inserir as mulheres na categoria de um corpo voltado à procriação e à perpetuação da espécie humana de exclusiva vocação à maternidade e à pureza da Virgem Maria.

Uma das garotas entrevistadas, Marli, reconhece-se como avessa a religiões. Em seu depoimento, inconscientemente, destaca como a crença [cristã] carregada do sentido de pureza a repele. Mediante tal afastamento, defende-se através de suas predileções pela "profana" indústria de entretenimento pop: "Não gosto nada da Bíblia, estou muito distante de Deus. Gosto das novelas, tramas policiais, drogas e pactos com o diabo.” Nesse sentido, podese explicar a dominação do cristianismo - sobretudo, o catolicismo advindo de Portugal e Espanha - em todo o território latino-americano. Sobre isso, comenta Alfredo Bosi:

A doutrina católica oficial, nesse limiar da modernidade leiga ou heterodoxa, que ao século da Renascença e da Reforma, procurava apagar os vestígios animistas ou mediúnicos do comportamento religioso. É o tempo da perseguição implacável à magia, tempo de caça às bruxas e aos feiticeiros, de resto não só na Espanha e em Portugal. (BOSI, 2006, p. 69)

De acordo com Silvia Federici, essa dominação é ancestral e remonta aos primeiros encontros com os colonizadores: 
Dividir e conquistar" também se tornou a política oficial nas colônias espanholas, depois de um período em que a inferioridade numérica dos colonos sugeria uma atitude mais liberal perante as relações interétnicas e as alianças com os chefes locais, por meio do casamento. No entanto, na década de 1540, na medida em que o aumento na quantidade de mestizos debilitava o privilégio colonial, a "raça" foi instaurada como um fator-chave na transmissão da propriedade, e uma hierarquia racial foi estabelecida para separar indígenas, mestizos e mulattos uns dos outros e da população branca [...] nas colônias sul-americanas se tornou possível uma certa "recomposição" especialmente entre as mulheres de classe baixa europeia, mestizas e africanas, que, além de sua precária posição econômica compartilhavam as desvantagens derivadas da dupla moral incorporada na lei, que as tornava vulneráveis ao abuso masculino (FEDERICI, 2017, p. 113).

Diálogos confusos acerca da religião, do casamento e da maternidade de diversas mulheres de várias idades e lugares completam a configuração da tônica do enredo que corrobora o discurso acerca das opressões de gênero. E a categoria mulher e mãe reaparece no testemunho de uma costureira, que aborda a maternidade em suas dificuldades de criação e sustento. Testemunho reforçado pelo depoimento de outra interna do reformatório, Jenny: "Nós, mulheres, sofremos muito. A mulher tem a dor de ser mãe, de ser filha. Os homens não sofrem o que sofremos." A terceira garota, Patrícia, ratifica as afirmações das companheiras de reformatório situadas entre os sonhos próprios da juventude e as frustrações diante da vida que lhes é oferecida. No entanto, o depoimento da jovem modelo Rosário, de 18 anos, parece alheio às opressões vivenciadas pelos testemunhos anteriores. Mas o contraste de seu biotipo talvez justifique sua fala que é chancelada por padrões de beleza europeus que se embatem com os da mulher tipicamente boliviana. Nesse sentido, outra condenação tênue constrói-se na medida em que as mulheres modelos e manequins vendem produtos comerciais e são domesticadas como produtos também à venda. Não possuem uma natureza a ser subjugada ou ainda mais violada. Segundo a pesquisadora Mariana Tavares, em seus documentários realizados fora do Brasil, Helena Solberg desconstrói a imagem da mulher sensual cujos traços europeus seriam supostamente superiores aos atributos físicos latino-americanos. Assim, o padrão construído pela mídia, em propagandas, revistas, filmes e novelas, estaria sendo confrontado (TAVARES, 2011, p. 24).

Após ter construído uma trajetória no cinema abordando questões de gênero e políticas na América Latina - e depois ter se voltado a outros motes políticos que não as pautas feministas -, Helena Solberg retoma, em 2017 e já de volta ao Brasil, temas ligados aos direitos das mulheres voltando-se à urgência das políticas públicas. Em Meu corpo, minha vida, a cineasta retrata a vida de Jandyra Magdalena dos Santos Cruz, uma jovem carioca de 
Campo Grande, no Rio de Janeiro. Crescida em meio aos cultos religiosos, a jovem ouviu a condenação de pastores afeitos a exorcismos e práticas similares. Um deles fornece depoimento à cineasta e afirma ter acompanhado a índole daquela garota já notoriamente predisposta ao pecado. Jandyra, independentemente das avaliações acerca dela, é levada à notoriedade, de fato, ao ter o corpo carbonizado após mutilação. As suspeitas recaíram imediatamente sobre os proprietários da clínica de aborto clandestina para onde a jovem se dirigiu após uma gravidez indesejada. E a moça já havia sido mãe ainda mais jovem.

O filme passa então a relacionar os diversos depoimentos de rostos midiaticamente famosos da cena brasileira, entre políticos, líderes religiosos e juristas. Entretanto, o julgamento da jovem é executado postumamente em ambiente público, como uma segunda morte, também de sua memória. Tal fato é analisado por Solberg para compreender a trajetória daquela mulher a reverberar gritos de tantas outras. Sua história servirá como o fio condutor do documentário que buscará reconstruir fissuras da formação brasileira desnudadas pelas violências diariamente cometidas contra as mulheres vítimas de crimes diversos que orbitam em torno do mote gênero. Estupros, feminicídios, abusos físicos e psicológicos, ainda praticados largamente nas sociedades contemporâneas, coadunam cultural e historicamente com o documentário realizado quarenta anos antes. Reverberam-se, presentificados na tragédia de Jandyra, outras Marlys, Patrícias e Jennys, como espectros ancestrais de refluxos históricos.

A abertura com imagens de passeatas na avenida Paulista (SP), com faixas, bandeiras e painéis embalados por coros de manifestantes - como "Machistas não passarão/Eu, passarinho/Fora Cunha", no mesmo cartaz -, pode englobar reinvindicações em pauta por meio das cenas do ano de 2015. Houve diversos protestos pelo país nos quais as mulheres reivindicavam o direito a seus corpos. A celeuma engendrou-se após o projeto de lei 5069 que dificultava o acesso ao aborto legalizado no Brasil, mesmo que apenas em caso de gravidez decorrente de violência sexual. Um dos autores, o deputado Eduardo Cunha $\left(\mathrm{PMDB}^{8}\right)$, foi uma das figuras cujos cartazes e palavras de ordem mais criticavam. O coro de "pela vida das mulheres" conduziria a narrativa fragmentada em mais cartazes como "No meu útero mando eu", etc.

Em São Paulo, o ato, que reuniu cerca de 2000 pessoas, segundo organizadoras do movimento, teve a presença de mães acompanhadas de suas filhas e também protesto em frente à Secretaria de Educação do Estado que tem um plano de reorganização de escolas no estado. No Rio de Janeiro,

\footnotetext{
${ }^{8}$ Sigla do Partido do Movimento Democrático Brasileiro (PMDB), que voltou a ser MDB desde 17 de dezembro de 2017, cuja ideologia costuma se afirmar "de centro", ou seja, moderado em tradições e conservadorismos.
} 
a marcha acabou na Cinelândia e também prestou uma homenagem às mulheres mortas após realizarem abortos inseguros - em 2014, dois casos chocantes aconteceram, em apenas um mês, na cidade (EL PAIS, 2015).

Dessa maneira, antes do primeiro minuto de filme, a situação se impõe: uma sociedade dividida entre os que se opõem aos valores morais aclamados por outros. Isso deflagra uma série de contradições, inclusive concernentes a uma formação como povo devido aos muitos retratos de Brasil apresentados. A seguir, para corroborar esses contrastantes discursos amparados na moralidade cívica e cristã, há as falas de um pastor de igreja com notoriedade nacional, e do ministro do Supremo Tribunal Federal desde 2013, Luís Roberto Barroso. Fica clara a oposição entre crenças fundamentalistas e as normas previstas pela Constituição Federal (1988).

Outra entrevistada, a jornalista Flávia Oliveira, pondera acerca dos direitos das próprias mulheres sobre seus corpos. A escritora Martha Medeiros reitera, inclusive, a existência milenar dos abortos. Os contrastes também são construídos em torno dos depoimentos de homens e mulheres sobre a questão e suas consequências legais, ilegais e condizentes à vida das mulheres em sociedade. A tais discursos segue-se a breve sequência de reconstrução da trajetória biográfica de Jandyra, a partir da festa de 15 anos - no Brasil, data considerada um marco na vida das adolescentes. A jovem já estava em sua primeira gestação, sendo moradora do subúrbio e criada em ambiente fervorosamente cristão. Nesse recorte parece residir a retomada de um assunto-chave: o das diferentes vivências de mulheres vitimadas por categorias que sobrepõem e mesclam faixas etárias, níveis sociais e origens étnico-raciais. Sobretudo na América Latina, como um dos berços da colonização.

O confronto de ideias proposto em filmes anteriores se repete em Меи corpo, minha vida, manifesto em depoimentos de juízes, advogados, pastores evangélicos, ativistas, escritores, profissionais da saúde, políticos, além de familiares de Jandyra. A cineasta chama a atenção para a urgência do debate a respeito da descriminalização do aborto no país. O documentário evidencia seu fôlego para prosseguir na realização de filmes que promovam discussões sobre diferentes aspectos da realidade brasileira, sempre com o olhar atento às questões femininas, sem perder de vista o contexto social, econômico e político nas Américas” (TAVARES, 2018, p. 99-100).

Ao mesmo tempo, há depoimentos de familiares (especificamente, a mãe, a irmã e o padrinho) e imagens de arquivo mescladas a entrevistas realizadas para o filme. Verifica-se que história da mãe de Jandyra repete a história de muitas meninas brasileiras, ao engravidar precocemente figurando entre as estatísticas que norteiam a segmentação etária, social e de 
gênero que conforma os dados oficiais do país. Dados de que " $20 \%$ são partos de adolescentes, 8\% meninas de até 15 anos e, às vezes, na segunda gestação", segundo o depoimento presente no documentário, de Anna Derraik, médica diretora do Hospital da Mulher Heloneida Studart. A constatação feita pelo excerto "Preservativo? Não é uma prática entre as mulheres jovens por diversas questões, como o segmento racial... religioso e social", abre margem para reflexões em torno das políticas de saúde pública e, mais profundamente, aos abismos educacionais existentes no país.

A influência das crenças neopentecostais corroboraria, de acordo com as hipóteses levantadas pelo filme, para o casamento e a formação precoces de família. O matrimônio entre Jandyra e seu primeiro companheiro, ambos da mesma comunidade, é mostrado como um dos retratos do abandono das jovens brasileiras de origem pobre. Em sua terceira gravidez, Jandyra Magdalena dos Santos Cruz decide recorrer ao medicamento Cytotec, cuja finalidade secundária era reconhecidamente a abortiva. $\mathrm{O}$ que se narra, após o cenário de horror inicial, é a simulação da execução - tiro na cabeça e esquartejamento - da jovem, feita para desvencilhar os culpados da prática clandestina de modo a confirmar discursos moralizantes e permeados, ao mesmo tempo, por hipocrisias e tradições.

O julgamento social após a repercussão da morte da jovem carioca e do grupo que agia ilegalmente, sendo também responsável por seu assassinato, condensará a revolta e a frustração populares. Seguem-se declarações de ativistas feministas, profissionais de saúde, juristas e outros rostos conhecidos midiaticamente para mostrar a diversidade de opiniões em torno do caso que reavivou discussões em torno do tema polêmico do aborto no Brasil. Amparadas pelo debate sobre a constatação de que, no país, é comum o contraste de que as "ricas abortam, pobres morrem" e "algumas mulheres têm direito ao seu corpo". Esse eixo narrativo conduz ao arremate da tese pautada pela desigualdade em diversos níveis a permear as relações sociais no Brasil impactado por crivo conservador, por mais que se retome, nesses momentos extremos, sua origem laica.

A reconstrução histórica realizada pelo documentário levanta a questão de que, na década de 1940, a lei existia para proteger o pai e a família. Ou seja, para que o filho de um estuprador não fosse criado pela família. Não havia a previsão de uma proteção à mulher estuprada. Ao mesmo tempo, ressalta que há um discurso contrário ao apregoado pela Igreja católica: acolher seria não criminalizar o aborto. A posição do filme continua na análise de que isso resvala em culpa religiosa, sobretudo quando não há uma formação tanto intelectual quanto familiar. Ao final, a maior consequência é a relativa ao descaso relegado à mulher. Um dos depoimentos alerta para o fato de que, se não existe ainda amparo do Estado brasileiro, 
pode-se compreender, de certa forma, a conivência oficial com as clínicas clandestinas de aborto. A prática, segundo o filme, desmente os discursos em favor da vida do feto e, portanto, contrários a qualquer reflexão sobre as políticas referentes aos direitos da mulher. Segundo outro advogado entrevistado, Pedro Abravomay, a criminalização das mulheres que decidiram recorrer a práticas abortivas é puni-las por se insurgirem contra os dogmas atribuídos à sua natureza biológica. E algumas pesquisas até presentes no site oficial do Senado brasileiro poderiam confirmar tais afirmações:

Na América Latina, há 182 milhões de gestações por ano das quais 36\% não são planejadas, quatro milhões de abortos, $21 \%$ das mortes maternas, 3,65 abortos por 100 mulheres entre 15 a 49 anos, $20 \%$ dos mortes maternas no Maranhão (1987-1991); o aborto inseguro é a primeira causa de morte materna em Salvador, Bahia, desde 1990; a terceira causa de morte materna em São Paulo; a quinta causa mais frequente de internação; o segundo procedimento obstétrico mais realizado; são 250 mil internações no SUS para tratamento de complicações (LANGER, 2002). São vários os motivos que levam a mulher a abortar: uma prole maior do que a planejada, dificuldades para se obter métodos anticonceptivos modernos, falta de orientação no planejamento familiar, pouca ou nenhuma instrução, comportamento sexual de alto risco, dentre outros. As mulheres ao serem impedidas de ter acesso à saúde por meio de tratamento adequado para o seu caso, em razão da forte carga de preconceito e intolerância acerca do procedimento do aborto, têm violada a sua honra e dignidade. Como ser humano, a mulher tem agredido um valor axiológico supremo, insculpido na Carta Magna (MORAIS, 2008, p. 56).

Dessa maneira, os dois documentários chamam a atenção para pontos que, muitas vezes, são esquecidos até propositadamente pela sociedade, especialmente quando suas relevâncias têm conexão com a necessidade de iniciativas que assegurem o direito das mulheres. As violências sexuais que acarretam casos de gravidez involuntária são, segundo ambos, ocorrências desamparadas pelo Estado. Isso reflete inevitavelmente a fragilidade do sistema público de saúde junto à falta de fomento a campanhas de educação e conscientização em torno de políticas públicas e medidas legislativas de amparo social. De modo a evitar o aumento do número de mortes anuais na América Latina, esses pontos são emergenciais e críticos. A alta mortalidade de mulheres alerta para a necessidade de medidas efetivas que impeçam a violência de gênero de maneira simbólica ou física por não terem direitos previstos por lei. A questão aparece mais incisiva ao serem confrontados dogmatismos: "Sendo o aborto a quarta causa de mortalidade materna, deve ser reavaliada a atenção que está voltada para a saúde da mulher, sem o comodismo da solução simplista de afirmar que o aborto é crime" (MORAIS, 2008, p. 57). 
Fazendo uma retrospectiva histórica, mesmo que somente na experiência do Brasil colonial, as mulheres sofreram perseguições religiosas por não serem cristãs ou por não submeterem seus corpos ao jugo público (e dos homens). O exemplo está no caso do Tribunal do Santo Ofício que, desde meados do século XVI, passou a atuar nas colônias como já o faziam em Portugal, e a partir da perseguição aos cristãos novos - ou judeus recém convertidos coercitivamente para burlar as perseguições cristãs, na Bahia primeiramente. De modo que as mulheres acusadas de feitiçaria eram perseguidas, inclusive, sob a acusação de práticas utilizadas que fugissem a uma imposição de conduta.

Para relacionar essas questões a acontecimentos da contemporaneidade e à perseguição das pautas acerca da mulher, é necessário remontar a uma pesquisa datada em uma década. Esta análise versa sobre a não continuidade da gravidez indesejada no Brasil, afinal, os dados oficiais de pesquisa tocam em fragilidades de aplicação real da lei. Clandestinamente existem clínicas de abortos disponíveis para quem dispõe de renda privilegiada:

A questão do aborto nas eleições em 2010 sinalizou a possibilidade de continuação e aprofundamento de um debate amplo e mais aberto. Os dados empíricos alinhados neste artigo contribuem para a adoção da tese de que a espiral do silêncio sobre a polêmica descriminalização diminuiu. Já há luz suficiente para uma discussão pública mais iluminada e mais iluminista. Este talvez seja o anseio de muitas brasileiras, tão bem expressado por uma jovem mulher, em pesquisa qualitativa realizada em 2010 pelo Ibope/Consórcio Bertha Lutz: 'a meu ver, o aborto já é uma coisa legalizada, o que está faltando é um pouco de dignidade da mulher quando ela vai ao médico fazer a curetagem, porque ela é trada feito um cachorro. Se a mulher tem dinheiro, ela vai a uma clínica, faz o aborto e vem pra casa; quando a mulher é pobre, ela faz um aborto de qualquer jeito em casa e quando vai ao hospital ela é maltratada. $\mathrm{O}$ aborto já existe, então tem que encarar como realidade, o que tem que ter é uma política pública que ajude a mulher (jovem mulher, 18 a 29 anos, Salvador) (BLAY; AVELAR, 2017, p. 316-317).

De acordo com a pesquisadora Débora Diniz, “...só uma mulher convicta de sua própria existência e projeto de vida se move contra a cadeia e o inferno para abortar em condições clandestinas na América Latina” (EL PAÍS, 2015). O aborto precisaria ser analisado, inclusive, em relação à violência de gênero exercida nos casos de estupros que, segundo pesquisa recente da filósofa Djamila Ribeiro, acomete meninas brasileiras entre 10 e 13 anos que são, em sua maior parte, negras e pobres. Outro alarmante dado que incorre novamente em questões relativas a políticas públicas atuantes. Tais iniciativas fariam frente ampla aos setores conservadores que justificam, por meio da moralidade, subterfúgios de 
controle que esbarram em práticas eugenistas de extermínio da população já mais vitimada pelas disparidades sociais.

\begin{abstract}
Segundo o Anuário Brasileiro de Segurança Pública de 2019, a cada hora quatro meninas de até 13 anos estupradas no país. Já segundo SUS, em média, ao menos 6 abortos por dia em meninas de dez a 14 anos. Sessenta e seis por cento dessas jovens são negras. $\mathrm{O}$ aborto é uma questão de saúde pública já que várias pesquisas apontam que morrem milhares de mulheres no Brasil todos os anos por causa de procedimentos inseguros as mulheres em sua maioria são negras e pobres uma vez que quem possui a condição econômica privilegiada paga por clínicas particulares. A visão que impõe uma moral e desconsidera a realidade do país só contribui para mais mortes (RIBEIRO, 2020).
\end{abstract}

De modo que é preciso levantar as questões centrais dos documentários de 1977 e 2017. Sobre a garantia de direito à reprodução de maneira planejada e controlada pela mulher que a permitiria, inclusive, ter inserção no mercado de trabalho como os homens ao disputar espaço profissional sempre sujeito a um projeto familiar e doméstico alheio a suas vontades. As crescentes reinvindicações acerca das diversas jornadas trabalhistas (formal ou informalmente) às quais as mulheres são submetidas só reiteram a necessidade de políticas públicas e efetivas que zelem pela busca e manutenção da equidade de gênero. Assim, seria possível construir-se uma sociedade em que os direitos, de fato, fossem usufruídos por todos os cidadãos no que se refere aos vários entrelaçamentos de categorias que podem colocar em risco uma livre mobilidade social. Dessa maneira, é preciso apreciar as pautas oriundas dos debates feministas e culturais como um fator crucial de luta nos países formados no cerne da colonização. E assim torna-se inquestionável o acompanhamento desses movimentos localizados em seus momentos históricos determinados:

Ainda que uma perspectiva distinta, o feminismo centrado no cuidado ou no maternalismo também é reticente sobre o direito ao aborto. Nesse caso, a compreensão de que a experiência diferenciada das mulheres contribuiria para uma ética centrada no cuidado, nas relações e na responsabilidade, em vez de uma ética centrada nos direitos, afasta as abordagens da própria noção de direito ao aborto como requisito para a autonomia das mulheres. Em alguns casos, destaca-se a tensão entre o direito das mulheres a escolher e as convenções da feminilidade, que incluiriam "a equação moral entre bondade e auto sacrifício. Em posições que se aproximam do ativismo católico contrário ao direito ao aborto o que é tomado como experiência singular, relacionada à maternidade e ao cuidado [...], posição desfavorável à autonomia das mulheres em relação ao aborto" (BIROLI, 2014, p. 125). 


\section{CONSIDERAÇÕES FINAIS}

Os filmes alertam, portanto, em uma perspectiva comparativa atrelada aos contextos históricos de produção, para questões mais prementes. Já que a dominação dos corpos femininos, através de certas convenções sociais, é um fenômeno histórico. A própria maternidade seria um mecanismo de controle da sexualidade e do corpo feminino. As mulheres, ao serem relegadas ao campo da natureza e não à história e à cultura, são destituídas de participação social. É como se as mulheres tivessem uma vida exterior a elas. Em suma, os homens produziriam cultura e história; já as mulheres estariam continuamente presas a lugares de subserviência devido ao controle impelido aos seus corpos; o que as ata a situações nas quais não podem exercer autonomia, e sempre a relegam ao desempenho de papel secundário e subalterno para suprir a necessidade do outro.

Sendo assim, a própria ideia da proibição do aborto, que pressupõe a incapacidade da mulher sobre seu corpo como presença na sociedade, perpetuaria a ideia da "menoridade" da mulher tanto em âmbito jurídico e filosófico quanto no recorte histórico. Parece, inclusive, ratificar a desconsideração de sua existência sempre pressuposta em respaldos cuja aversão ao seu gênero a mantivesse continuamente reprimida e culpada por suas reações diante das omissões de políticas públicas capazes de assegurar seus direitos perante o Estado. Nesse sentido, a degradação social estaria atrelada a uma lógica imperativa de mercado disposta a subjugar as relações sociais e as condições trabalhistas deflagrando a precariedade do sistema político e econômico que se vale ainda da exploração de uma população vulnerável socialmente para manter seus lucros. E as mulheres são relegadas à exploração desde as primeiras ocupações destas terras. Para extração das riquezas, da "máquina mercante" do poeta baiano do barroco brasileiro, Gregório de Matos, ao aludir sonoramente "aos nossos ouvidos de hoje, como uma arguta metonímia do sistema inteiro, o mercantilismo" (BOSI, 2006, p. 96), alude-se à “Triste Bahia” que era o Brasil colonial do século XVII.

Assim, a filmografia de Solberg retoma acontecimentos que esboçam tentativas de compreensão de um país afeito à reprodução das mazelas de sua conjuntura formativa desde os primórdios da colonização. Entre exclusões diversas que resvalam em preconceitos sexistas, racistas e, principalmente, atrelados a fatores econômicos que norteiam as diversas interpretações atribuídas às mulheres latino-americanas. E pode contribuir para o questionamento das bases que engendram estruturas sociais em constante embate - e observação - dos momentos históricos. 


\section{REFERÊNCIAS}

A ENTREVISTA. Direção: Helena Solberg. Brasil, 1966, p\&b, 19 min.

BLAY, E.; AVELAR, L. (Org.) 50 anos de feminismo: Argentina, Brasil e Chile. São Paulo: Edusp, 2017.

BOSI, Alfredo. Dialética da colonização. São Paulo: Companhia das Letras, 2006

CLÜVER, Claus. "Estudos Interartes: conceitos, termos e objetivos". Revista Literatura e Sociedade. DTLLC - FFLCH -USP, v. 2 n. 2, 1997, pp. 37-55.

CLÜVER, Claus. “Intermidialidade”. Pós: vol.1, n.2, 2008, pp. 8-23.

DINIZ, Débora. “Aborto um sentimento de alívio”. In: El País. 17 jan. 2020. Disponível em: Acesso em: 07/08/2020.

EL PAÍS. "Mulheres protestam contra Cunha pela terceira vez em duas semanas", 12 nov 2015 Disponível em:

https://brasil.elpais.com/opiniao/2020-01-17/aborto-um-sentimento-dealivio.html\#?sma=newsletter brasil20200118https://brasil.elpais.com/brasil/2015/11/12/politi ca/1447346906 965515.html Acesso em: 05/08/2020.

FEDERICI, Silvia. Calibã e a bruxa: mulheres, corpo e acumulação primitiva. Trad.: Coletivo Sycorax. São Paulo: Ed. Elefante, 2017.

FIGUEIREDO, Vera Lúcia Follain de. Narrativas migrantes: literatura, roteiro e cinema. Rio de Janeiro: PUC-RIO, 2010.

FREYRE, Gilberto. Casa-grande\&snzala. 51. ed. São Paulo: Editora Global, 2003.

FRIEDAN, Betty. A mística feminina. Petrópolis: Editora Vozes limitadas, 1971.

GONZÁLEZ, Lélia. "Por um feminismo afrolatinoamericano". Revista Isis Internacional, Santiago, v. 9, p. 133-141, 1988.

HOLANDA, Karla. TEDESCO, Marina Cavalcanti. Feminismo e plural: Mulheres no cinema brasileiro. Campinas, SP: Papirus, 2017.

HOLLANDA, Heloísa Buarque. Pensamento feminista hoje: Perspectivas decoloniais. Rio de Janeiro: Bazar do Tempo, 2020.

LEENHARDT, Jacques. "Jean Baptiste Debret: um olhar francês sobre os primórdios do império brasileiro". Rev. Sociologia \& Antropologia. Rio de Janeiro, v.03.06: 509-523, novembro, 2013.

LISPECTOR, Clarice. “Amor”, in: Laços de Família. Rio de Janeiro: Rocco, 1998.

LUGONES, María. “Colonialidad y género” In: Tabula Rasa. Bogotá, n. 9, p. 73-101, julio- 
diciembre, 2008.

METZ, Christian. Linguagem e cinema. São Paulo: Editora Perspectiva, 1980.

MEU corpo, minha vida. Direção: Helena Solberg. Brasil, 2017, cor, 90 min.

MIGUEL, Luis Felipe. BIROLI, Flávia. Feminismo e política. São Paulo: Boitempo, 2014.

MORAIS, Lorena. “A legislação sobre o aborto e seu impacto na saúde da mulher”. Senatus, Brasília, v. 6, n. 1, p. 50-58, maio 2008. Disponível em: https://www2.senado.leg.br/bdsf/bitstream/handle/id/131831/legisla\%C3\%A7\%C3\%A3o aborto impacto.pdf?sequence $=6$. Acesso em: 24.08.2020.

ORTIZ, Renato. Cultura Brasileira e identidade nacional. São Paulo: Brasiliense, 2006.

RIBEIRO, Djamila. "Descriminalizar aborto é desafiar privilégios concedidos aos homens" Folha de São Paulo 20 ago. 2020.

Disponível em: https://www1.folha.uol.com.br/colunas/djamilaribeiro/2020/08/descriminalizar-aborto-e-desafiar-privilegios-concedidos-aos-homens.shtml Acesso: 23.08.2020.

ROCHA, Glauber. “Uma estética da fome”, in: Revista Civilização Brasileira, n.3, jul. 1963.

RODRIGUES, Nelson. "Inimiga pessoal da mulher”, In: O reacionário: memórias e confissões. São Paulo: Cia das Letras, 1995.

SIMPLESMENTE Jenny. Direção: Helena Solberg. Estados Unidos, 1975, cor, 53 min.

TAVARES, Mariana. Helena Solberg: trajetória de uma documentarista brasileira. Tese de Doutorado. Escola de Belas Artes. UFMG. Belo Horizonte, 284 p. 2011. 